\begin{tabular}{ccc}
\hline & International Journal of Engineering \& Technology, $7(2.15)(2018) 111-114$ \\
SPC & International Journal of Engineering \& Technology \\
Website: $w w w . s c i e n c e p u b c o . c o m / i n d e x . p h p / I J E T$ & Research Paper \\
\hline
\end{tabular}

\title{
Development of café web-based system using priority scheduling approach
}

\author{
Fatimah Ghazali*, Rohana Ismail, Mohamad Hariz Hasni \\ Faculty of Informatics and Computing, Universiti Sultan Zainal Abidin, Besut Campus, 22200 Besut, Terengganu, Malaysia \\ *Corresponding author E-mail: fatimah@unisza.edu.my
}

\begin{abstract}
Manual food ordering system requires on many employees to handle ordering process. It can be dull and disorganized, and can end up with data irregularity for generating sales report. Moreover, the total time taken for food preparations is longer. Therefore, the café web based system is developed using priority scheduling algorithm to reduce the duration in ordering process, handling and preparing bulk and concurrent order, and at the same time minimizing the cost of handling employees. The priority scheduling algorithm is based on Control Processing Unit scheduling algorithm where it has a priority to execute tasks in waiting queue. The system is implemented at UniSZA's café where it will be used by café owner and UniSZA students. This system is developed based on three-tier architecture. The JSP, JavaScript, Java and MySQL have been employed to improve manual ordering management. Initially, the preliminary testing shows that the priority scheduling algorithm has a potential to exchange the traditional ordering system.
\end{abstract}

Keywords: Café web based system; Food ordering system; Priority scheduling; Web-based system.

\section{Introduction}

Many restaurants around the world still using manual ordering systems in their restaurant. The manual food ordering systems normally will depend on number of employee to support the business functions such as ordering food, reservation, inquiry, placing order and reminding dishes [1]. It can be accidently switch details between orders and end up with irregularity in data entry for generating reports.

Due to an increasing awareness of the internet and its related technologies, restaurants can take the opportunity to bring up their businesses online. One of such business is an online food ordering system. The customers will be exposed to the online businesses where placing an order can be made via online. The online business is very convenient because customers will be provided with detailed information on the products or items offered such as price, quality and products' dimensions and specifications. This is supported by user friendly and simplified interface for customer to place order online. Previously, efforts had been made to substitute the traditional ordering process into online ordering process. For example, a food ordering system based on PDA- wireless [2]. However, this system still require waiters to take order. In fact, it only replaced paper and pen by using PDA. Another early system is a food ordering system with real time customer feedback [3]. This system requires smart phone for the customer to make order. Another system is a waiter paging system [4]. The customers use the system to call a waiter. The current study is designed to exchange traditional ordering process, but still using traditional ordering process to order the food. Therefore, this study has been done to develop an online ordering system which will improve the weakness of previous system. In fact, the system uses a priority scheduling algorithm for effective online ordering process.
In this system, customer can directly make orders from the system and miscommunication between customers and waiters can be reduced. Moreover, it also improves the restaurant chef section by providing projected time for food preparation. The system uses priority scheduling algorithm for detecting which menu needs to be served first in order to reduce time consumed for cooking. Apart from that, it is implemented at UniSZA's café where students and owner of the cafe will use the system. The implementation of café web based system used the JSP, JavaScript, Java and MySQL.

This paper has the following organization. In section 2 explains the related food ordering system and priority scheduling approach are given. Next, the café web based system architecture is presented and followed by café web based implementation using priority scheduling. After that, the experimental results of the algorithm proposed discuss in this paper with other algorithms are also presented in section 5. Lastly, end with the conclusion.

\section{Related work}

Predictably, food ordering system uses the paper based system, where all records for order and payment are stored on paper. The paper can easily misplaced and scratched. Since paper-based systems have limitation, it does not afford any form of dynamicity. The system totally depend on big numbers of employee to handle customer reservation, inquiry, ordering food, placing order and reminding dishes [5]. Since large employee is required, this system is error-prone and is time consuming from a customer's point of view [6].

The previous studies proposed the development of food ordering system using technology such as PC, PDA, multi-touchable [2] and smart phone based on Android [7-9]. The modules consist of order food before visiting restaurant, book table, makes payment, realtime feedback between the restaurant owner and customers [3]. The 
system will reduce waiting time and misunderstanding can be reduced to minimal [1]. However, most of the development of food ordering systems focus on customer and cashier side. But on the kitchen side, it only displays the ordered menu. It does not cater food preparation time.

In order to overcome this drawback, we propose the priority scheduling algorithm to schedule the food preparation. Priority scheduling is a non-preemptive algorithm and one of the most common scheduling algorithms in batch systems. Each process is assigned a priority. Process with highest priority is to be executed first and so on. Processes with same priority are executed on first come first served basis. Priority can be decided based on memory requirements, time requirements or any other resource requirement [10]. The objectives of scheduling are to maximize throughput, avoid indefinite blocking or starvation, minimize overhead, enforcement of priority, achieve balance between response and utilization, favour processes exhibits desirable behaviour and degrade gracefully under heavy load [10-11].

\section{Café web based system architecture}

Café web based system is designed based on three-tier client-server architecture. The architecture for the Café Web based system shown in Figure 2. The Café System page will be display when users or students enter the system as presentation layer. The page contains all information of the Café and also the promotion price if any. Users can navigate through the system to find their preferred menu. Then, user can place order based on their preferred menu. They can add and remove their prefered menu and the system will display the total cost automatically is presented in business logic layer. All orders are store in database as database layer.

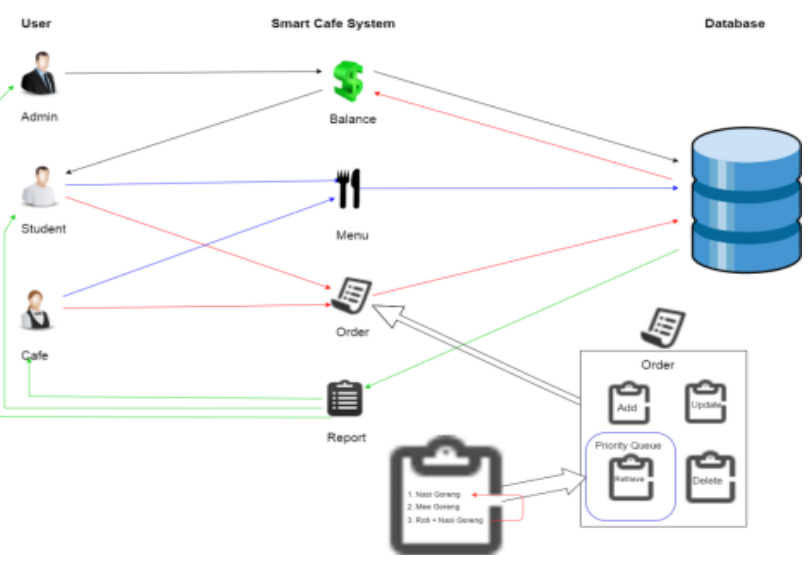

Fig. 1: Architecture of Cafe Web based system

Figure 2 shows the basic of priority queue flow implement in business logic layer. First, every new order will be added into the ready queue. The order will be added based on per assigned priority value. Then, the highest priority order will be served. After the highest priority is successfully processed it will be released or in other word will be terminated from ready queue.

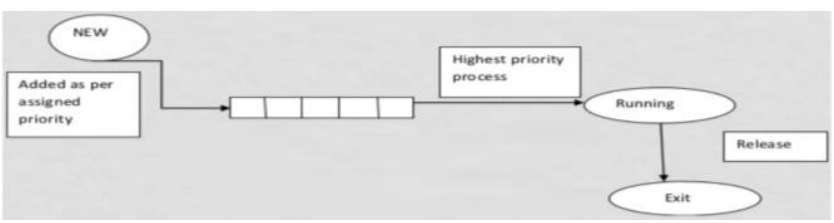

Fig. 2: Priority scheduling

Table 1 shows a priority scheduling algorithm is implemented in Café-Web based system during the process of queue the order list that will be displayed to Café which is made by student. The same with the first order queue list will be set into the highest priority. In addition of that, for the length of queue that will implement priority queue which is called ready queue, will be set into fix number to prevent the queue for the order that has being updated need to wait for a long time to be serving.

Table 1: Priority scheduling algorithm

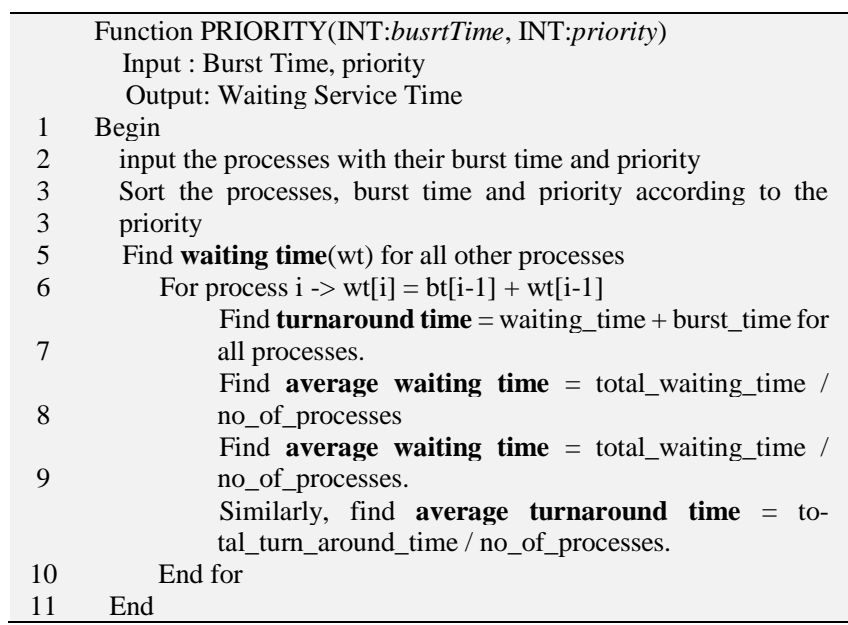

\section{Café web based system implementation}

System implementation the process of getting the system operating properly, including installation, configuration, running, testing and making any necessary changes.

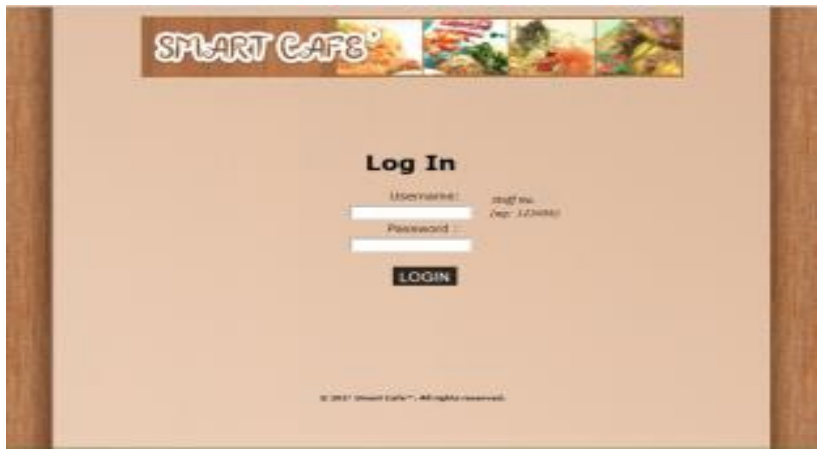

Fig. 3: Login form

Figure 3 shows the login page for two main users, which is Admin and Café. The username will be their employee id. The login page is designed to login into the system.

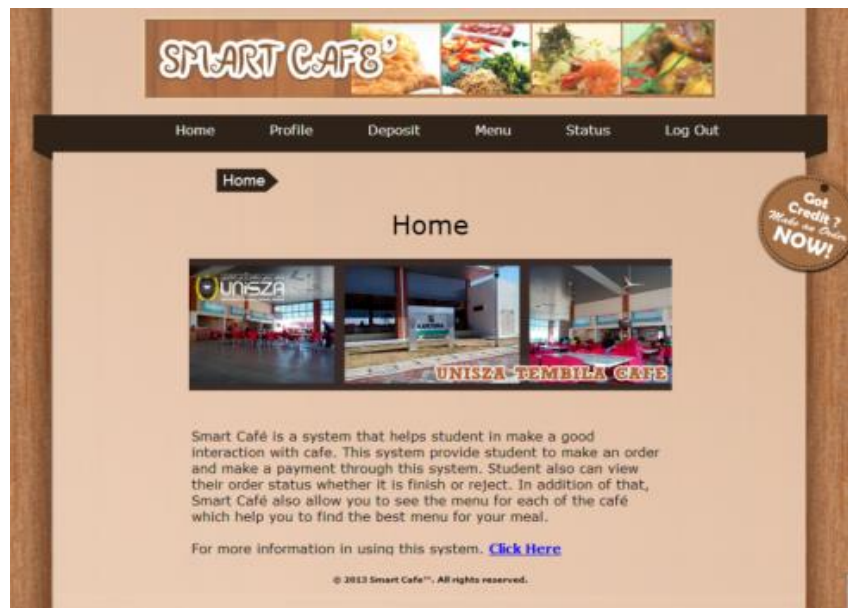

Fig. 4: Homepage 
Figure 4 shows the student Home Page. This will be the first page that the student will navigate after a successful login. There is information about the system for students to explore. In addition, students also can click at "Click Here" to automatically download user manual guideline.



Fig. 5: Order form for students

Figure 5 shows a front page for student to choose menu. Student will see all menus that café provided. Students can make order by ticking at "Order" then enter quantity for the menu. After filling the Receipt Menu then student need to click at "Order Now" button.

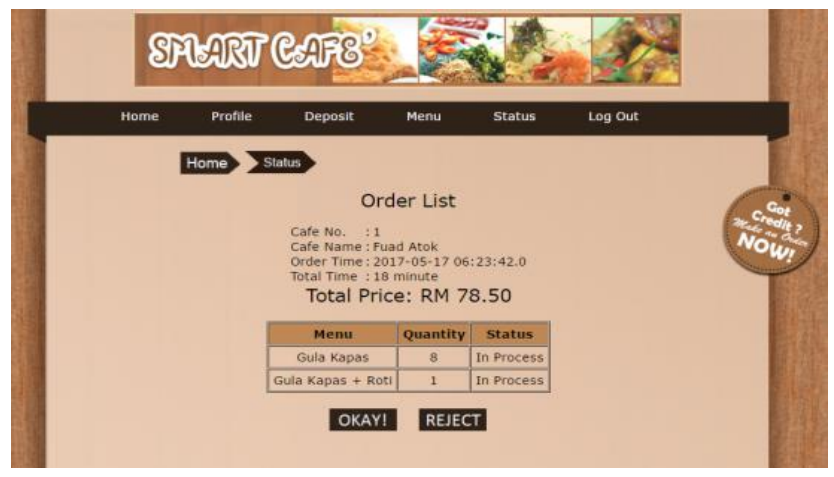

Fig. 6: Confirmation order from student

Figure 6 shows a page for student to confirm their order after finish fill in the menu form. In this page student will see all order details such as Café No, Café Name, Order Time, Total Time and Total Price. If the student wants to proceed with the order, he/she needs to click "Okay!" button or if he/she wants to cancel the order he/she can click at the "Reject" button.

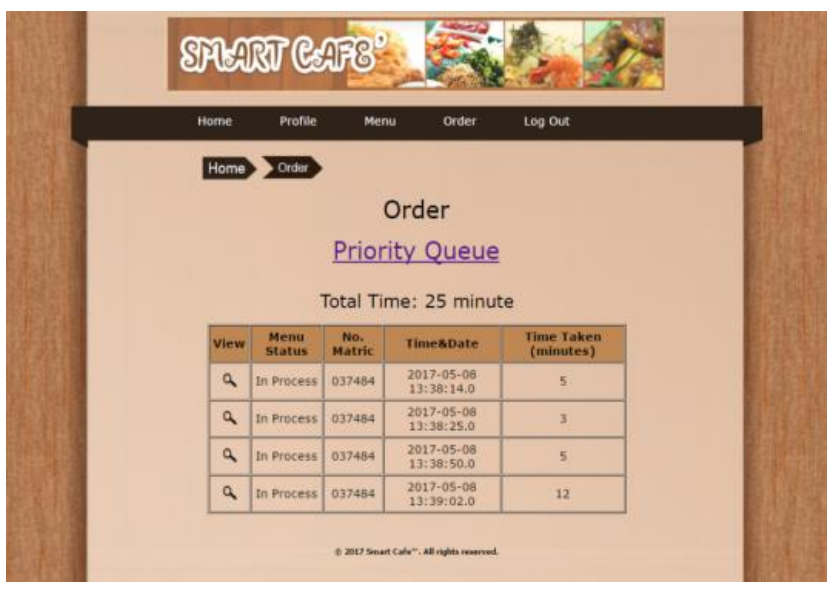

Fig. 7: List of ordered menu for kitchen employee

Figure 7 shows a page for kitchen cafe to handle the order based on First Come First Serve algorithm. In this page all the order that has being made by students to the café will appear in the table provided. The café has two options either to handle the order list by First Come First Serve algorithm or by using Priority algorithm. The Café can see the details of the order by clicking at "View" icon.

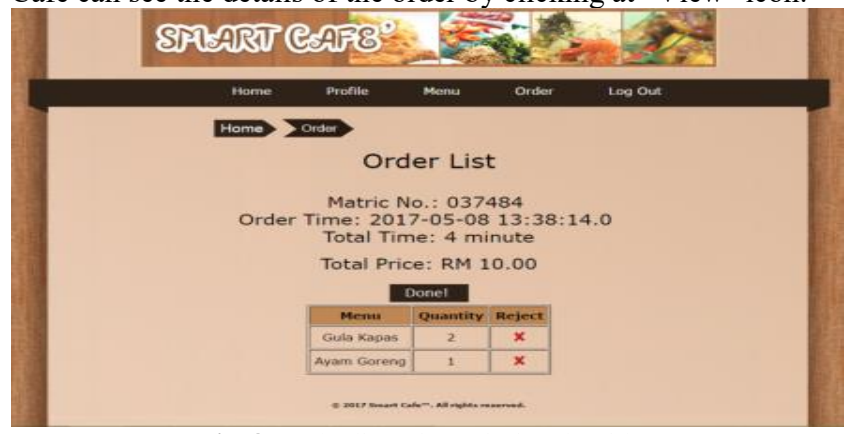

Fig. 8: Order list using priority algorithm

Figure 8 shows a page for cafe to see the order details from student. The café will have two options either to make the order status done by clicking at the "Done!" button after finishing serve the order or reject the certain order.

\section{Results and discussion}

The functionality of all modules in cafe web based system has been tested. The result of the test shown in Table 2.

Table 2: Result of Café web based System Analysis

\begin{tabular}{c|c|c}
\hline Test Module & Expected Result & Actual Result \\
\hline $\begin{array}{c}\text { Initializing systems by } \\
\text { adding all items into } \\
\text { database }\end{array}$ & $\begin{array}{c}\text { All items can be viewed in } \\
\text { database and ready to be }\end{array}$ & Success \\
$\begin{array}{c}\text { used } \\
\text { Update the password }\end{array}$ & $\begin{array}{c}\text { system verifies username } \\
\text { and password }\end{array}$ & Success \\
$\begin{array}{c}\text { Add, remove and up- } \\
\text { date preferred item } \\
\text { into table }\end{array}$ & $\begin{array}{c}\text { List of item of menu and } \\
\text { successfully } \\
\text { adds a new } \\
\text { menu }\end{array}$ \\
\hline
\end{tabular}

Table 2 shows the 5 concurrent ordered with estimation food preparation time and priority is set for each order. The overall time for preparing all ordered menus is 75 minutes. We schedule these ordered menus according to the Table 2 by using first come first serve and priority scheduling. Two ordered fried rice menus are combined to be one menu. The kitchen employee prepares the fried rice once for two orders. It shows that time taken for preparing food is 60 minutes. We make a comparison with first come first serve algorithm. The result shows that the food preparation time reduces 15 minutes compared to first come first serve algorithm. Overall, it reduces the food preparation time by maximizing the food ordering and minimizing the numbers employee involved.

Table 3: Ordered menu

\begin{tabular}{c|cccc}
\hline Ordered Menu & Time Order & Food Preparation Time & Priority \\
\hline Fried Rice & 0 & $15 \mathrm{~min}$ & 1 \\
Mee Sup & 0 & $15 \mathrm{~min}$ & 2 \\
Fried Mee & 0 & $15 \mathrm{~min}$ & 3 \\
Nasi Paprik & 0 & $15 \mathrm{~min}$ & 4 \\
Fried Rice & 0 & $15 \mathrm{~min}$ & 1 \\
\hline
\end{tabular}

Table 4: Comparison of food preparation time between without priority and with Priority Scheduling Algorithm

\begin{tabular}{c|cccccc|c}
\hline $\begin{array}{c}\text { Ordered } \\
\text { Menu }\end{array}$ & $\begin{array}{c}\text { Fried } \\
\text { Rice }\end{array}$ & $\begin{array}{c}\text { Mee } \\
\text { Soup }\end{array}$ & $\begin{array}{c}\text { Fried } \\
\text { Mee }\end{array}$ & $\begin{array}{c}\text { Nasi } \\
\text { Paprik }\end{array}$ & $\begin{array}{c}\text { Fried } \\
\text { Rice }\end{array}$ & \multirow{2}{*}{$\begin{array}{l}\text { Without } \\
\text { Priority }\end{array}$} \\
$\begin{array}{c}\text { Food } \\
\text { preparation } \\
\text { Time }\end{array}$ & 15 & 30 & 45 & 60 & 75 & \\
\hline $\begin{array}{c}\text { Ordered } \\
\text { Menu }\end{array}$ & Fried & Mee & Fried & Nasi & & \\
\cline { 1 - 5 } $\begin{array}{c}\text { Food } \\
\text { preparation } \\
\text { Time }\end{array}$ & 15 & 30 & 45 & 60 & & $\begin{array}{c}\text { With Pri- } \\
\text { ority }\end{array}$ \\
\hline
\end{tabular}




\section{Conclusion}

This paper has presented the development of online food ordering system for UniSZA's café. The online system will improve the manual systems in terms of time and employee. The inconsistency of data entry for ordering process will be reduced, hence it will efficiently generate all related reports. Moreover, the priority scheduling has been demonstrated to reduce time taken for food preparation services. It will help cooking for managing ordering process. As priority scheduling will contributes to starvation, future work will be focusing on agent based improvement to enhance the priority scheduling.

\section{Acknowledgement}

Special thanks to Faculty of Informatics and Computing and Universiti Sultan Zainal Abidin (UniSZA) for conference support and funding.

\section{References}

[1] Noor MZ, Rahman AA, Saaid MF, Ali MS \& Zolkapli M (2012), The development of Self-service Restaurant Ordering System (SROS). Proceedings of the IEEE Control and System Graduate Research Colloquium, pp. 348-353.

[2] Cheong SN, Chiew WW \& Yap WJ (2010), Design and development of Multi-touchable E-restaurant Management System. Proceedings of the IEEE International Conference on Science and Social Research, pp. 680-685.

[3] Tanpure SS, Shidankar PR \& Joshi MM (2013), Automated food ordering system with real-time customer feedback. International Journal of Advanced Research in Computer Science and Software Engineering 3, 220-225.

[4] Green D \& Curtis J (2002), Restaurant waiter paging system. United States patent US 6,366,196.

[5] Zhang J \& Chen X (2012), Research and design of embedded wireless meal ordering system based on SQLite. Physics Procedia 25 , 583-587.

[6] Dhore VB, Thakar S, Kulkarni P \& Thorat R (2014), Digital table booking and food ordering system using Android application. International Journal of Emerging Engineering Research and Technology 2, 76-81.

[7] Poonam K, Priya K, Snehal K \& Ingale PB (2016), Self-served food ordering system. Imperial Journal of Interdisciplinary Research 2 , 1311-1316.

[8] Bhargave A, Jadhav N, Joshi A, Oke P \& Lahane SR (2013), Digital ordering system for restaurant using Android. International Journal of Scientific and Research Publications 3, 1-7.

[9] Ricky MY (2014), Mobile food ordering application using Android OS platform. EPJ Web of Conferences 68, 1-8.

[10] Silberschatz A, Galvin PB \& Gagne G (2014), Operating system concepts essentials. John Wiley and Sons.

[11] Rajput IS \& Gupta D (2012), A priority based round robin CPU scheduling algorithm for real time systems. International Journal of Innovations in Engineering and Technology 1, 1-11. 